\title{
Perubahan Penggunaan Lahan Sawah Menjadi Lahan Kelapa Sawit di Kecamatan Tanjung Mutiara
}

\author{
Juliawan Kelvin ${ }^{1}$, Triyatno ${ }^{2}$, Febriandi ${ }^{3}$ \\ Program Studi Geografi, \\ FIS Universitas Negeri Padang \\ E-mail: Juliawankelvin21@gmail.com
}

\begin{abstract}
Abstrak
Penelitian ini bertujuan untuk. 1) untuk mengetahui luas perubahan penggunaan lahan sawah menjadi lahan kelapa sawit. 2) untuk mengetahui faktor yang mempengaruhi perubahan penggunaan lahan. 3) untuk mengetahui tingkat kesejateraan petani kelapa sawit. Jenis penelitian ini adalah deskriptif dengan pendekatan kuantitatif. Jenis data yang digunakan pada penelitian ini adalah data primer dan data sekunder. Teknik analisis yang digunakan yaitu analisis overlay pada analyst ArcGis 10.2, Analisis Hirearki Process (AHP), dan analisis Indeks Kemiskinan menurut BPS tahun 2016. Hasil dari penelitian ini yaitu : 1) Perubahan luas lahan sawah menjadi lahan kelapa sawit dalam 10 tahun yaitu sebesar $619 \mathrm{Ha}$, 2) faktor yang mempengaruhi perubahan penggunaan lahan yaitu faktor ekonomis dengan nilai $74,6 \%, 3$ ) tingkat kesejahteran petani kelapa sawit yaitu dari 54 responden ada 35 responden atau $64,8 \%$ responden memiliki tingkat kesejahteraan tinggi dan 19 responden atau $35,2 \%$ responden memiliki tingkat kesejahteraan sedang.
\end{abstract}

Kata kunci : Perubahan penggunaan lahan, Faktor perubahan lahan, Tingkat kesejateraan.

\begin{abstract}
The aims of research are. 1) To know the extent of land use change of the twice field become palm field 2) To know about influencing factor of land use change 3) To know the prosperity of palm's farmer degree. The type of this research is descriptive with quantitative approach. The type of data used of prmary data and secondary data. The technique of analysis used is overlay analysis on Arcgis analist 10.2, analysis hierarki process (AHP) and analysis poverty degree based on BPS 2016. The results of this research are 1) Land use change of rice field become palm field on $10^{\text {th }}$ years is about 619 hectare. 2) The influencing factor of land use change is economic factor with in 71,6\% 3) The prospereties of palm's farmer from 54 respondents are 35 respondents or $64,8 \%$ in high degree and 19 resondents or $35,2 \%$ respondents in low degree.
\end{abstract}

Keywords : The change of land's use, faktors of land's use, level of welfare

\footnotetext{
${ }^{1}$ Mahasiswa Program Studi Geografi

${ }^{2,3}$ Dosen Jurusan Geografi Fakultas Ilmu Sosial Universitas Negeri Padang
} 


\section{PENDAHULUAN}

Berkembangnya pembangunan ekonomi di Indonesia yang telah membangkitkan tingginya permintaan akan kebutuhan terhadap lahan dari tahun ke tahun. Karena lahan merupakan sumber daya yang terbatas, alih fungsi dari pertanian ke non pertanian (pemukiman, industri, sarana umum dan sebagainya) tidak dapat dihindari. Pemanfaatan kawasan sepanjang sungai dan sumber air lain oleh masyarakat yang tidak berfungsi sebagaimana mestinya, menunjukan betapa lahan menjadi sumber daya yang langka (Purwanto, 2015).

Perubahan penggunaan lahan secara tidak langsung adalah dampak dari pertumbuhan ekonomi nasional. Hal ini penting untuk mengevaluasi perubahan penggunaan lahan dalam konteks regional dan konteks lokal untuk mengantisipasi dampak yang berhubungan dengan lingkungan langsung (Briassoulis H. 2000). Verburg et al. (2002) mengembangkan pemodelan spasial untuk perubahan penggunaan lahan pada areal lebih kecil dari nasional atau provinsi.

Lahan sawah memiliki arti yang sangat penting dalam upaya mempertahankan ketahanan pangan. Seiring perkembangan zaman, pertambahan penduduk, dan tuntutan ekonomi, eksistensi lahan pangan mulai terusik. Salah satu permasalahan yang cukup serius saat ini berkaitan dengan lahan pangan adalah makin maraknya alih fungsi lahan pangan menjadi penggunaan lainnya (Blaikie P. and Brookfield $\mathrm{H}$ ,1987). (Chapin,F.Stuart dan Edward J. Kaiser, 1979), memberikan pengertian lahan pada dua skala yang berbeda yaitu lahan pada wilayah skala luas dan pada konteks skala urban.

Berdasarkan Undang-undang Nomor 41 Tahun 2009 tentang Perlindungan Lahan Pertanian Pangan Berkelanjutan, Pemerintah telah melakukan pengaturan tentang alih fungsi lahan, yaitu perubahan fungsi Lahan Pertanian Pangan Berkelanjutan menjadi bukan Lahan Pertanian Pangan Berkelanjutan baik secara tetap maupun sementara akan dikenakan hukuman pidana dan denda sesuai dengan ketentuan yang berlaku. Namun hal tersebut belum dapat diimplementasikan dengan baik di lapangan. Perubahan penggunaan lahan ditentukan oleh interaksi khusus dan sementara antara faktor biofisik dan faktor antropogenik (Veldkamp dan Fresco, 1996).

Kecamatan Tanjung Mutiara sebagai salah satu Kecamatan di Kabupaten Agam, secara astronomis Kecamatan Tanjung Mutiara terletak pada $100^{\circ} 22^{\prime} \mathrm{BT}$ dan $0^{\circ} 03^{\prime}$ LS. Luas Kecamatan Tanjung Mutiara adalah $205,73 \mathrm{~km}^{2}$ atau sekitar 9,22 persen dari total luas Kabupaten Agam. Berbatasan sebelah Utara dengan Kabupaten Pasaman Barat, Timur berbatasan dengan Kecamatan Lubuk 
Basung dan Kecamatan Ampek Nagari, Selatan dengan Kabupaten Padang Pariaman, sebelah Barat dengan Samudera Hindia. Pada umumnya mata pencaharian penduduk di Kecamatan Tanjung Mutiara adalah sebagai nelayan dan perkebunan untuk penduduk yang tinggal di pesisir barat (BPS Kabupaten Agam 2016).

Kelapa sawit dapat tumbuh dengan baik di daerah tropis $\left(15^{\circ} \mathrm{LU}\right.$ - $15^{\circ}$ LS). Tanaman ini tumbuh sempurna di ketinggian 0-500 $\mathrm{m}$ dari permukaan laut dengan kelembaban 80-90\%. Sawit membutuhkan iklim dengan curah hujan stabil, 2000$2500 \mathrm{~mm}$ setahun, yaitu daerah yang tidak tergenang air saat hujan dan tidak kekeringan saat kemarau. Pola curah hujan tahunan mempengaruhi perilaku pembungaan dan produksi buah sawit (Tanaman kelapa sawit secara umum cocok untuk ditanam pada lahan dataran rendah di Kecamatan Tanjung Mutiara.

Terjadinya alih fungsi lahan sawah menjadi tanaman kelapa sawit disebabkan oleh beberapa hal yaitu pendapatan usaha tani kelapa sawit lebih tinggi dengan resiko lebih rendah, nilai jual/agunan kebun lebih tinggi, biaya produksi usahatani kelapa sawit lebih rendah, dan terbatasnya ketersediaan air. Menunjukkan pendapat yang rendah di suatu sektor atau kurangnya keberagaman dalam hidup menjadi alasan perubahan penggunaan lahan di seluruh dunia (Ostwald, 2008 dalam Bello, 2014).

Salah satu dampak dari konversi lahan sawah yang sering menjadi sorotan masyarakat luas adalah terganggunya ketahanan pangan. Selain fungsi positif, pengelolaan lahan sawah yang kurang memperhatikan kai-dah konservasi dan pelestarian ekologi lingkungan berpotensi menimbulkan dampak atau fungsi negatif. (Jacobsen et al., 1981; Cicerone and Shetter, 1983; Holzapfel-Pschoer et al, 1986).

Masalah yang ditimbulkan bersifat permanen atau tetap akan terasa dalam jangka panjang meskipun konversi lahan sudah tidak terjadi lagi (Irawan, 2005). Land use adalah tujuan manusia dalam mengeksploitasi land cover (Lambin et al. 2003. (Veldkamp et al. 2001) analisis pola peng-gunaan lahan eksisting dan lampau untuk menentukan variabel paling penting dari aspek biogeofisik dan sosial ekonomi.

Untuk mencegah terjadinya alih fungsi lahan secara tidak terkendali, pengambil kebijakan harus memiliki data dan informasi yang memadai terkait dengan faktorfaktor yang mempengaruhi petani melakukan alih fungsi lahan (Laymo, 2003). Memecah perusahaan besar menjadi usaha-usaha kecil tidak selalu akan meningkatkan kesejahteraan masyarakat. Dalam meningkatkan kesejahteraan sosial 
menjadi pekerjaan yang lebih rumit dan tidak mudah dipahami (Kramer, R, 1986 dalam Chrisine Miligan, 2004). Kesejahteran masyarakat sering diartikan pada programprogram pemerintah yang memberikan bantuan pada individu2 atau keluarga yang membutuhkan (Hasson, S. and Ley, D. 1994).

Oleh karena itu dalam tulisan ini dipaparkan hasil identifikasi tentang luas perubahan lahan pangan menjadi lahan kelapa sawit dan faktor-faktor apa saja yang mendorong petani melakukan alih fungsi lahan, serta sejauh manakah pergeseran penggunaan lahan mempengaruhi tingkat kesejahteraan petani.

Lahan merupakan suatu daerah dipermukaan bumi dengan sifat-sifat tertentu yang meliputi biosfer, atmosfer, tanah, lapisan geologi, hidrologi, populasi tanaman, binatang dan hasil kegiatan manusia masa lalu dan masa sekarang sampai pada tingkat tertentu. Sifat-sifat tersebut mempunyai pengaruh yang berarti terhadap penggunaan lahan oleh manusia pada masa sekarang dan masa yang akan datang (FAO, 1976).

Perubahan penggunaan lahan merupakan perubahan fungsi sebagian atau seluruh kawasan lahan dari fungsi semula (seperti yang direncanakan) menjadi fungsi lain yang jadi dampak negatif (masalah) terhadap lingkungan atau lahan itu sendiri. Lahan merupakan sumber daya alam yang memiliki fungsi sangat luas dalam memenuhi berbagai kebutuhan manusia. Dari sisi ekonomi, lahan merupakan input tetap yang utama dari berbagai kegiatan produksi komonitas pertanian maupun non pertanian.

\section{METODE PENELITIAN}

Dalam penelitian ini digunakan metode deskriptif kuantitatif dengan pendekatan populasi sampling dan untuk pengolahan data digunakan analisis data spasial penginderaan jauh. Penelitian deskriptif merupakan penelitian yang bertujuan untuk mengumpulkan informasi mengenai status suatu gejala yang ada yaitu keadaan gejala menurut apa adanya pada saat penelitian dilakukan (Arikunto, 1989).

Cara untuk mencapai tujuan adalah dengan menggunakan (a) Analisis perubahan penggunaan lahan dilakukan dengan overlay peta sehingga diketahui perubahan penggunaan lahan yang terjadi pada tahun 2007-2017 (b) Menurut Badan Pusat Statistik (2016) dalam mengetahui tingkat kesejahteraan ada delapan, yaitu pendapatan, konsumsi atau pengeluaran rumah tangga, keadaan tempat tinggal, fasilitas tempat tinggal, kesehatan anggota keluarga, kemudahan memasukkan anak kejenjang pendidikan, dan kemudahan mendapatkan fasilitas tranportasi (c) Analisis data yang digunakan untuk faktor perubahan lahan lahan sawah menjadi lahan kelapa sawit adalah Analysis 
Hierarchy Process (AHP). Menurut Saaty (1993), metode AHP mampu memecahkan permasalahan yang terstruktur maupun kompleks (tidak terstruktur) dengan data dan informasi yang terbatas. Elemenelemen penyusun hirarki ditentukan berdasarkan diskusi dengan pemilik kebun. Elemen-elemen tersebut kemudian dinilai berdasarkan perbandingan secara berpasangan dengan menggunakan skala komparasi.

\section{HASIL DAN PEMBAHASAN Perubahan Luas Lahan Sawah Menjadi Lahan Kelapa Sawit}

Berdasarkan hasil Analisis Citra Landsat TM5 Tahun 2007 dan Citra Landsat +OLI/TIRS Tahun 2017 dan setelah dilakukan Overlay pada peta penggunaan lahan tahun 2007-2017 maka diperoleh hasil peta perubahan penggunaan lahan kawasan sawah yang menjadi kelapa sawit tahun 2007 dan 2017 serta pengamatan secara langsung di lapangan dan diperoleh perubahan penggunaan lahan kawasan sawah yang menjadi kelapa sawit.

Hasil klasifikasi disajikan dalam bentuk tabel agar memudahkan dalam membedakan perubahan yang terjadi dapat dilihat pada tabel 1 perubahan luas penggunaan lahan dibawah ini.

Tabel 1. Perubahan Penggunaan Lahan

\begin{tabular}{llllll}
\hline No & Klasifikasi & $\begin{array}{l}\text { Tahun } \\
2007 \\
(\mathrm{Ha})\end{array}$ & $\begin{array}{l}\text { Tahun } \\
2017(\mathrm{Ha})\end{array}$ & $\begin{array}{l}\text { Perubahan } \\
\text { Luas 2007- } \\
2017\end{array}$ & Keterangan \\
\hline 1 & $\begin{array}{l}\text { Kelapa } \\
\text { Sawit }\end{array}$ & 12.954 & 13.573 & 619 & $(+)$ \\
\hline 2 & Sawah & 1.398 & 779 & 619 & $(-)$ \\
\hline Jumlah & 14.352 & 14.352 & 1.238 & \\
\hline
\end{tabular}

\section{Sumber: Pengolahan Data Primer Tahun 2018}

Dari tabel 1 di atas, dapat dilihat bahwa perubahan luas penggunaan untuk kawasan lahan kelapa sawit kecamatan tanjung mutiara selalu mengalami pening-katan dari tahun 2007. Hal ini dapat dilihat bahwa luas lahan kelapa sawit di kecamatan tanjung mutiara pada tahun 2007 yaitu 12.954 ha meningkatan menjadi 13.573 ha pada tahun 2017, berarti terjadi penambahan luas kelapa sawit dari sawah sebesar 619 ha selama 10 tahun terakhir. Berdasarkan hasil analisis dapat diketahui bahwa pada tahun 2007 luas sawah yaitu 1.398 ha dan pada tahun 2017 menurun menjadi 779 ha, artinya terjadi penurunan sebesar 619 ha.

Dapat disimpulkan bahwa perubahan penggunaan lahan untuk kawasan kelapa sawit kecamatan tanjung mutiara tahun 2007 dan 2017 selalu meningkat dari tahun ke tahun, kondisi ini disebabkan karena adanya perubahan penggunaan lahan dari 
lahan sawah menjadi lahan kelapa sawit sehingga lahan kelapa sawit pada tahun 2007 yang terdapat pada lahan berubah letaknya pada lahan kelapa sawit karena adanya perubahan fungsi lahan.

Hasil dari perubahan penggunaan lahan sawah menjadi lahan

Gambar 1. Peta perubahan lahan sawah menjadi lahan kelapa sawit

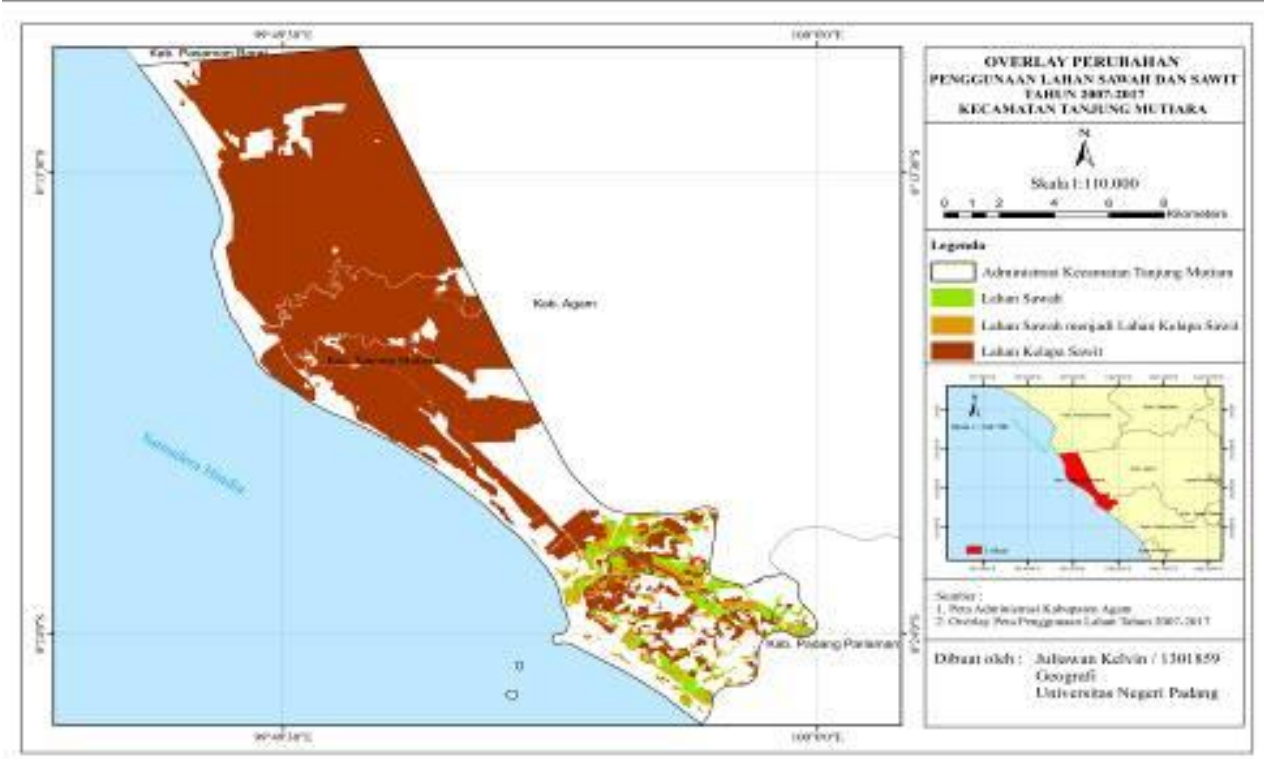

Sumber : Analisis data penggunaan lahan tahun 2007 dan tahun 2017

\section{Faktor Perubahan Lahan}

Setelah didapatkan hasil matrik perbandingan berpasangan selanjutnya yaitu menghitung nilai eigen vector dan menguji konsistensinya, jika tidak konsisten maka pengambilan data (prefensi) perlu diulangi. Nilai eigen vector yang dimaksud adalah nilai eigen vector maksimum yang diperoleh.

Berdasarkan analisis data maka dari hasil perhitungan diperoleh faktor yang paling mempengaruhi masyarakat di Kecamatan Tanjung Mutiara yaitu : kelapa sawit di Kcamatan Tanjung Mutiara pada tahun 2007 sampai tahun 2017 dapat dilihat pada gambar 1 peta perubahan lahan dibawah ini: 


\section{Tingkat Kesejahteraan Petani Kelapa Sawit}

Tingkat kesejahteraan petani di Kecamatan Tanjung Mutiara dapat dilihat dari tabel 2 berikut : ngetahuan tentang pengelolaan sumber daya kelapa sawit untuk kesejahteraan masyarakat perlu dikembangkan.

Tabel 2. Tingkat Kesejahteran Petani Kelapa Sawit

\begin{tabular}{lllll}
\hline No & \multicolumn{1}{c}{ Kategori } & Jumlah Skor & \multicolumn{1}{c}{$\begin{array}{c}\text { Jumlah } \\
\text { Responden }\end{array}$} & $\begin{array}{c}\text { Presentase } \\
(\%)\end{array}$ \\
\hline 1 & $\begin{array}{l}\text { Tingkat Kesejahteraan } \\
\text { Tinggi }\end{array}$ & $20-24$ & 35 & 64,8 \\
\hline 2 & $\begin{array}{l}\text { Tingkat Kesejahteraan } \\
\text { Sedang }\end{array}$ & $14-19$ & 19 & 35,2 \\
\hline 3 & $\begin{array}{l}\text { Tingkat Kesejahteraan } \\
\text { Rendah }\end{array}$ & $8-13$ & - & - \\
\hline \multicolumn{3}{c}{ Jumlah } & 54 & 100 \\
\hline & \multicolumn{3}{c}{ Sumber : Pengolahan Data Primer 2018 }
\end{tabular}

Sumber : Pengolahan Data Primer 2018

Dari tabel 2 di atas dapat dilihat tingkat kesejahteraan dari lahan kelapa sawit masyarakat, dari 54 responden, ada 35 responden atau $64,8 \%$ responden yang mempunyai tingkat kesejahteraan yang tinggi dan 19 responden atau $35,2 \%$ responden mempunyai tingkat kesejahteraan yang sedang. Berdasarkan ketiga indikator yang digunakan tersebut pada dasarnya menunujukkan bahwa sebagian besar petani kelapa sawit di Kecamatan Tanjung Mutiara tergolong kedalam keluarga yang taraf hidupnya sejahtera.

Dalam melakukan penanaman kelapa sawit masyarakat sudah mengetahui bahwa dari hasil kelapa sawit tersebut bisa meningkatkan taraf kesejahteraan masyarakat itu sendiri. Hasil dari kebun kelapa sawit yang cukup menjanjikan membuat masyarakat lain semakin banyak melakukan penanaman kelapa sawit, meningkatkan pe-
Dari hasil penelitian dilapangan, maka pembahasan dari perubahan lahan, faktor perubahan penggunaan lahan dan tingkat kesejahteraan masyarakat di Kecamatan Tanjung Mutiara yaitu:

Dapat dilihat pada bahwa perubahan luas penggunaan untuk kawasan lahan kelapa sawit Kecamatan Tanjung Mutiara selalu mengalami peningkatan dari tahun 2007. Hal ini dapat dilihat bahwa luas lahan kelapa sawit di Kecamatan Tanjung Mutiara pada tahun 2007 yaitu 12.954 ha meningkatan menjadi 13.573 ha pada tahun 2017, berarti terjadi penambahan luas kelapa sawit dari sawah sebesar 619 ha selama 10 tahun terakhir. Berdasarkan hasil analisis dapat diketahui bahwa pada tahun 2007 luas sawah yang ada yaitu 1.398 ha dan pada tahun 2017 menurun menjadi 779 ha, artinya terjadi penurunan sebesar 619 ha. 
Dapat disimpulkan bahwa perubahan penggunaan lahan untuk kawasan kelapa sawit di Kecamatan Tanjung Mutiara tahun 2007 dan 2017 selalu meningkat dari tahun ke tahun, kondisi ini disebabkan karena adanya perubahan penggunaan lahan dari lahan sawah menjadi lahan kelapa sawit.

Berdasarkan hasil analisis data tentang faktor yang paling mempengaruhi terhadap perubahan penggunaan lahan pangan menjadi lahan kebun kelapa sawit terbagi atas aspek ekonomis, aspek lingkungan, dan aspek teknis. Dari hasil pengolahan data diketahui berdasarkan faktor-faktor penyebab pertimbangan petani dalam melakukan perubahan penggunaan lahan dipengaruhi oleh aspek ekonomis $\quad(39,1 \%)$, selanjutnya diikuti oleh aspek teknis $(31,4 \%)$, dan aspek lingkungan $(29,5 \%)$. Bila dilihat dari pengaruh faktor-faktor penyebab, maka faktor yang paling mem-pengaruhi perubahan penggunaan lahan adalah faktor ekonomis.

Dalam Undang-undang Nomor 41 Tahun 2009 tentng Perlindungan Lahan Pertanian Pangan Berkelanjutan. Pemerintah telah melakukan pengaturan tentang alih fungsi lahan, yaitu perubahan fungsi Lahan Pertanian Pangan Berkelanjutan menjadi bukan Lahan Pertanian Pangan Berkelanjutan baik secara tetap maupun sementara akan dikenakan hukuman pidana dan denda sesuai dengan ketentuan yang berlaku. Namun hal tersebut belum dapat diimplementasikan dengan baik dilapangan.

Berdasarkan peraturan dalam UU No 41 Tahun 2009 tersebut, masyarakat di Kecamatan Tanjung Mutiara masih belum bisa mengiplementasikan hal tersebut. Perubahan penggunaan lahan yang terjadi dikarenakan oleh faktor ekonomis dari lahan kelapa sawit tersebut dimana aspek ekonomis terdiri atas (1) harga jual tanaman pangan yang rendah khususnya pada saat panen, (2) panen kelapa sawit dilakukan secara kontinue 2 minggu sekali panen, (3) keuntungan dari berkebun sawit lebih tinggi dari tanaman pangan, (4) harga sawit lebih terjamin dan stabil daripada harga tanaman pangan, dan (5) biaya pemeliharan dari tanaman sawit lebih rendah.

Dari hasil analisis data dilapangan tingkat kesejahteraan dari lahan kelapa sawit masyarakat, dari 54 responden, ada 35 responden atau $64,8 \%$ responden yang mempunyai tingkat kesejahteraan yang tinggi dan 19 responden atau 35,2\% responden mempunyai tingkat kesejahteraan yang sedang. Berdasarkan ketiga indikator yang digunakan tersebut pada dasarnya menunujukkan bahwa sebagian besar petani kelapa sawit di Kecamatan Tanjung Mutiara tergolong kedalam keluarga yang taraf hidupnya sejahtera. 
Dalam melakukan penanaman kelapa sawit masyarakat sudah mengetahui bahwa dari hasil kelapa sawit tersebut bisa meningkatkan taraf kesejahteraan masyarakat itu sendiri. Hasil dari kebun kelapa sawit yang cukup menjanjikan membuat masyarakat lain semakin banyak melakukan penanaman kelapa sawit, meningkatkan pengetahuan tentang pengelolaan sumber daya kelapa sawit perlu dikembangkan.

\section{PENUTUP}

\section{Kesimpulan}

Sesuai dengan deskriptif data, analisa data, dan pembahasan hasil penelitian maka dari penelitian ini dapat peneliti ambil kesimpulan. Perubahan luas lahan sawah menjadi kelapa sawit di Kecamatan Tanjung Mutiara pada tahun 2007 yaitu 12.954 ha meningkatan menjadi 13.573 ha pada tahun 2017, berarti terjadi penambahan luas kelapa sawit dari sawah sebesar 619 ha selama 10 tahun terakhir. Berdasarkan hasil analisis dapat diketahui bahwa pada tahun 2007 luas sawah yaitu 1.398 ha dan pada tahun 2017 menurun menjadi 779 ha, artinya terjadi penurunan sebesar 619 ha. Berdasarkan hasil analisis data tentang faktor yang paling mempengaruhi terhadap perubahan penggunaan lahan sawah menjadi lahan kebun kelapa sawit terbagi atas aspek ekonomis, aspek lingkungan, dan aspek teknis. Dari hasil pengolahan data diketahui ber- dasarkan faktor-faktor penyebab pertimbangan petani dalam melakukan perubahan penggunaan lahan dipengaruhi oleh aspek ekonomis $(39,1,2 \%)$, selanjutnya diikuti oleh aspek teknis $(39,4 \%)$, dan aspek lingkungan $(29,5 \%)$. Bila dilihat dari pengaruh faktor-faktor penyebab, maka faktor yang paling mem-pengaruhi perubahan penggunaan lahan adalah faktor ekonomis. Tingkat kesejahteraan dari petani lahan kelapa sawit, dari 54 responden, ada 35 responden atau $64,8 \%$ responden yang mempunyai tingkat kesejahteraan yang tinggi dan 19 responden atau 35,2\% responden mempunyai tingkat kesejahteraan yang sedang. Berdasarkan ketiga indikator yang digunakan tersebut pada dasarnya menunujukkan bahwa sebagian besar petani kelapa sawit di Kecamatan Tanjung Mutiara tergolong kedalam keluarga yang taraf hidupnya sejahtera.

\section{DAFTAR PUSTAKA}

Badan Pusat Statistik. 2016. Tanjung Mutiara Dalam Angka . Penerbit Badan Pusat Statistik. Agam.

Bello I. K and Arowosegbe O.S. 2014. Factors Affecting Land-Use Change on Property Values in Nigeria. Journal of Research in Economics and International Finance (JREIF) (ISSN: 2315-5671) Vol. 3(4) pp. 79 82. November, 2014. 
Blaikie P. and Brookfield H. (1987).

Land Degradation and Society. 296 pp. London: Routledge. This is an exemplary sociopolitical and institutional analysis of the causes of land degradation. Vol. 1 Hal : 1-94.

Briassoulis H. (2000). Analysis of Land Use Change: Theoretical and Modelling Approaches. The Web Book of Regional Science, Scott Loveridge, ed. Regional Research Institute, West Virginia University, USA. Vol. 1 Hal. 4-6.

Chapin F. Stuart and Edward J. Kaiser.1979. Urban Land Use Planning University Chicago: University of Illionis Press. Vol. 59:1759-1769.

Christine Milligan And Nicholas R. Fyfe. 2004. Putting the Voluntary Sector in its Place:Geographical

Perspectives on Voluntary Activity and Social Welfare in Glasgow. Jnl Soc. Pol. 33, 1, 73-93. Cambridge University Press.

Cicerone, R.J. and J.D. Shetter. 1983. Sources of atmospheric methane: measurement in rice paddies and a discussion. J. Gheophys. Vol. 86: 72037209.

Food and Agriculture Organization ,(1976). Aframework for land evaluation FAO Soil Bull.
No. 32, Rome, $72 \mathrm{pp}$; and ILRI Publication No. 22, Waginengen, $87 \mathrm{pp}$.

Hasson, S. and Ley, D. (1994), Neighbourhood

Organisations and the Welfare State, Toronto: Toronto University Press. Vol. 25 No. 4 Hal. 463-82.

Holzapfel-Pschorn, A.R., R. Conrad, and W. Seiler. 1986. Effect of vegetation on the emission of methane from submerged paddy soil. Plant Soil. Vol. 92 : $223-233$

Irawan, B. 2005. Konversi Lahan Sawah menimbulkan Dampak Negatif bagi Ketahanan Pangan dan Lingkungan. Warta Penelitian dan Pengembangan Pertanian Vol. 27 No. 6 tahun 2005. Pusat Analisis Sosial Ekonomi dan Kebijakan Pertanian. Bogor.

Jakobsen, P., W.H. Patrick, Jr., and B.G. Williams. 1981. Sulfide and mathane formation in soils and sediments. Soil Sci Vol. 132: Hal. 279-287.

Kurdianto, D. 2011. Alih Fungsi Lahan Pertanian ke Tanaman Kelapa Sawit. http://uripsantoso.wordpress. com.

Lambin, E. F., Geist, H. J., \& Lepers, E. (2003). Dynamics of landuse and land-cover change in tropical regions. Annual 
review of environment and resources, 28(1), 205-241.

Laymon, C., 2003. Satellite Remote Sensing of Land Use Change. Universities Space Research Association National Space Science and Technology Centre 320 Sparkman, Huntsville, Alabama 35805. Jul 23, 2003.

Purwanto, A. N., Ernawati, J., \& Wijaksono, A. D. The Factors of Land use Conversion from Settlement Area to Commercial Area at IR. Soekarno/Merr Street, Rungkut Street, and Medokan Ayu Street, Surabaya. Indicator, 3, 4, 2015.
Indonesia, R. (2009). Undangundang Republik Indonesia nomor 41 tahun 2009 tentang Perlindungan Lahan Pertanian Pangan Berkelanjutan. Jakarta: Republik Indonesia.

Veldkamp, A., Verburg, P. H., Kok, K. G. H. J., De Koning, G. H. J., Priess, J., \& Bergsma, A. R. (2001). The need for scale sensitive approaches in spatially explicit land use changemodeling. Environmen tal Modeling \& Assessment, 6(2), 111-121.

Veldkamp A, Fresco L (1996). A Conceptual Model of Study the Conversion of Land Use and its effects. Ecological Model. J. Vol. 85:253-270. Vitonset DM. 